$\S=-1$

\title{
Enhancement of Graphite Functionality in Renewable Polymer Composite Properties
}

\author{
Nur Munirah Abdullah ${ }^{1}$,A. Z. M. Rus ${ }^{1}$, M. F. L. Abdullah ${ }^{2}$ \\ ${ }^{I}$ Sustainable Polymer Engineering, Advanced Manufacturing and Materials Center (SPEN-AMMC), Faculty of Mechanical and Manu- \\ facturing Engineering, Universiti Tun Hussein Onn Malaysia, 86400 Parit Raja, Batu Pahat, Johor, Malaysia \\ ${ }^{2}$ Department of Communication Engineering, Faculty of Electrical and Electronic Engineering, Universiti Tun Hussein Onn Malaysia, \\ 86400 Parit Raja, Batu Pahat, Johor, Malaysia \\ *Corresponding author E-mail: nurmunirahabdullah87@gmail.com, zafiah@uthm.edu.my, faiz@uthm.edu.my
}

\begin{abstract}
The preparation and characterization of composite thin films of renewable polymer graphite (PG) is disclosed. Thin films $\sim 0.1 \mathrm{~mm}$ thick are prepared using a simple solution mixing with mass proportion of 2/1 (renewable monomer/ Methylene Diphenyl Diisocyanate, MDI), upon differ graphite content $\left(\mathrm{PG}_{0}, \mathrm{PG}_{5}, \mathrm{PG}_{10}, \mathrm{PG}_{15}, \mathrm{PG}_{20}, \mathrm{PG}_{25}\right.$ and $\left.\mathrm{PG}_{30}\right)$ and drop casting at room temperature. The morphology-structure relations of renewable PG composites with respect to electrical conductivity were diagnosed using Optical microscope (OM), Fourier transform infra-red spectroscopy (FTIR) and Thermogravimetric analysis (TGA). The homogeneous random dispersion and strong interface between the graphite in the classical insulating renewable polymer matrix were observed. Thus resulting of enhancements in thermal stability with slight shift of decomposition temperature and better mechanical properties through the modulus and tensile strength increment up to $\sim 440 \%$ and $\sim 100 \%$ respectively. The result shows that it can simultaneously leads to renewable PG conductivity $(\sigma)$ where the percolation threshold occurs at higher graphite content $\left(\mathrm{PG}_{20}, \mathrm{PG}_{25}\right.$ and $\left.\mathrm{PG}_{30}\right)$ of $10^{3}-10^{4} \mathrm{~S} / \mathrm{m}$. Thus, this non-petroleum based renewable polymer graphite composites have remarkably more to offer as conducting polymer composites material in multidisciplinary applications.
\end{abstract}

Keywords: Renewable polymer graphite; interconnected interface; thermal stability; mechanical behavior; insulating-conductive.

\section{Introduction}

Advantages of renewable polymer composites recently prominent over polymer composites due to being biocompatible, biodegradability and improving sustainability. Eventhough fossil fuels basedorigin can generate huge amounts of electricity efficiently, the long term effects causes environmental pollution (non-degradable) and poses environmental hazards has catch the eye for decades. Thus, renewable polymer from renewable resources can be used as reliable starting material to access new products as abundant availability and relatively low cost make an industrially attractive for the plastic industry. Despite that, polymeric materials either organic or non-organic based are normally electrical insulator in their nature, limitates its usage as a smart material under electrical conducting application. These drawbacks have lead to the growth in the research for electrically conductive polymer material. At present, favourable filler like carbon black (CB) [1], carbon nanotubes [2-4], activated carbon [5] and graphene [6-8] has changed the classical renewable polymer as insulator into conductive polymer composites (CPCs). Moreover, CPC have many advantages over metallic conductors. They can be easily modified with low cost technologies; light weight; provide corrosion resistance and offer a wide range of electrical conductivities such as thermal interface materials [9-10] dye-sensitized solar cell [11], bipolar plates in proton exchange membrane (PEM) fuel cells [12], electronic [13-14] etc. However, these filler are expensive in production, high viscosity caused by entangled tubes, aggregation, high anisotropic functionality and toxicity in which lead to a challenge in the dispersion and exfoliation of graphene in a media especially with polymer matrix. In order to achieve optimal enhancement in the property of CPC, improved dispersion and surface modification of filler in polymer matrix for good interconnected interface are the key issues. Alternately, graphite consists of layers of graphene whereby carbon-carbon atoms are covalently bonded in the same plane whilst each planes are weakly bonded by van der Waal's forces [15-16]. The superior properties, such as excellent conductive properties, generated from two-dimensional graphene based sheets make graphite an excellent candidate for electrical and thermal management systems [17].

Due to well dispersion of graphite in polymer matrix, in [18] reported that by adding expandable graphite (EG) in polyurea (PU) accelerates the decomposition reaction of the composites and promotes more char (thermally stable) than its neat PU. It was also reported that with addition of $4.4 \mathrm{wt} \%$ of graphite oxide nanoplatelets ( GONPs), a significant increased up to $\sim 900 \%$ and $\sim 327 \%$ for the Young's modulus and hardness of the polyurethane (PU) respectively [19]. In the former case, in [20] work on in situ formation of graphite nanosheets state that, uniform dispersion of graphite nanosheets in expendable/ epoxy nanocomposite attributed to an improvement of elastic modulus over its neat epoxy properties. Furthermore, the interconnected particles in the polymer matrix trigger conductivity as describe in previous work [21]. In situ polymerization of in acid medium followed by increment of expanded (1, 2 and $3 \mathrm{wt} \%$ ) was synthesized to form a series of conducting polyaniline / expanded graphite (PA/EG) composite. The recorded dc electrical conductivities of the PA/EG composites were dramatically increased from $0.50 \times 10^{2} \mathrm{~S} / \mathrm{cm}$ to $6.11 \times 10^{2} \mathrm{~S} / \mathrm{cm}$ compared to neat polyaniline [22]. This phenom- 
enon can be explained by theory of percolation. At low filler loading, the conducting particles are separated and the electric current facing difficulties to flow through a non-conducting medium. As the filler loading increased, the gaps between conducting particles diminish and start to form pathways for electrical conductivity [23]. Nevertheless, there is a small number of studies regarding dispersion of graphite in renewable polymer from renewable resources.

Therefore, in this research, graphite/ catalytic ring-opening polymerization of the epoxides (vegetable oil) will be used to form polyols (renewable monomer) that will reacts with crosslinker to form renewable polymer thin film composites. The influence of the graphite content towards the renewable polymer morphology are also investigated, correlate with thermal, mechanical and electrical conductivity properties.

\section{Methodology}

\subsection{Materials}

The graphite flakes used in this research for the preparation of renewable PG composite as supplied by May \& Baker Ltd. The used of virgin cooking oil (VCO) as renewable monomer preparation, whilst all other chemicals and reagents for the acid-catalyst preparation are of SYSTERM ChemAR. The Methylene Diphenyl Diisocyanate (MDI) from ALDRICH was used as renewable monomer cross-linker.

\subsection{Graphite Preparation}

The flake graphite mixture (with acid sulfuric acid, $\mathrm{H}_{2} \mathrm{SO}_{4}$ is placed into a flask in the ultrasonic cleaning bath and undergoes sonication for 60 minutes at room temperature. After the sonication, yellow solution presence indicating a high oxidation of graphite. The precipitate of graphite mixture was collected and washed to neutrality with water (confirmed via $\mathrm{pH}$ paper), dehydrated, and dried in an oven. This approach has been adopted from previous work [24] and the process is simplified in Figure 1.
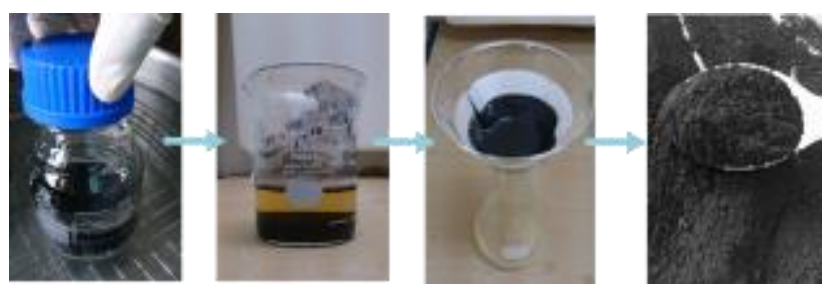

Fig. 1: Preparation of graphite content.

\subsection{Renewable Monomer Preparation}

Starting renewable monomer conversion begins with few steps using virgin cooking oil (VCO): the preparation of in-house catalyst in which to promote the monomer from the unsaturated compound and the acid-catalyst ring opening of the epoxide to form renewable polymer. $[25,26]$. In this experiment, $1 \mathrm{~L} /$ run of virgin cooking oil that been used and chemically manipulated at laboratory scale form $1 \mathrm{~L}$ of renewable monomer.

\subsection{Renewable Polymer Graphite (PG) Composites Preparation}

The graphite- renewable polymer thin film composites were prepared by mixing the renewable monomer and a crosslinker, Methylene Diphenyl Diisocyanate (MDI) with an increase of $5 \mathrm{wt}$. \% of prepared graphite namely $\mathrm{PG}_{0}, \mathrm{PG}_{5}, \mathrm{PG}_{10}, \mathrm{PG}_{15}, \mathrm{PG}_{20}, \mathrm{PG}_{25}$ and $\mathrm{PG}_{30}$ respectively as in Table 1 . The viscous mixture was then poured into a container, slip casted and readily left dried at room temperature for about 6 hours [21]. Later, the films were peeled off and submitted for film characterization. The G-RP films thickness was measured using micrometer which ranging $\sim 0.1 \mathrm{~mm}$ as shown in Figure 2.



Fig. 2: Preparation of renewable $\mathrm{PG}_{0}, \mathrm{PG}_{5}, \mathrm{PG}_{10}, \mathrm{PG}_{15}, \mathrm{PG}_{20}, \mathrm{PG}_{25}$ and $\mathrm{PG}_{30}$ composites.

Table 1: Sample preparation with differ weight percentage (wt.\%) of graphite loading.

\begin{tabular}{|c|c|c|c|}
\hline Sample & Components & Weight ratio & Weight percent (wt/wt\%) \\
\hline $\mathrm{PG}_{0}$ & $\begin{array}{c}\text { Monomer/ } \\
\text { MDI/ Graphite }\end{array}$ & $2 / 1 / 0$ & 0 \\
\hline $\mathrm{PG}_{5}$ & $\begin{array}{c}\text { Monomer/ } \\
\text { MDI/ Graphite }\end{array}$ & $2 / 1 / 0.1$ & 10 \\
\hline $\mathrm{PG}_{10}$ & $\begin{array}{c}\text { Monomer/ } \\
\text { MDI/ Graphite }\end{array}$ & $2 / 1 / 0.2$ & 15 \\
\hline $\mathrm{PG}_{15}$ & $\begin{array}{c}\text { Monomer/ } \\
\text { MDI/ Graphite }\end{array}$ & $2 / 1 / 0.3$ & 20 \\
\hline $\mathrm{PG}_{20}$ & $\begin{array}{c}\text { Monomer/ } \\
\text { MDI/ Graphite }\end{array}$ & $2 / 1 / 0.4$ & 25 \\
\hline $\mathrm{PG}_{25}$ & $\begin{array}{c}\text { Monomer/ } \\
\text { MDI/ Graphite }\end{array}$ & $2 / 1 / 0.5$ & 30 \\
\hline $\mathrm{PG}_{30}$ & $\begin{array}{c}\text { Monomer/ } \\
\text { MDI/ Graphite }\end{array}$ & $2 / 1 / 0.6$ & 25 \\
\hline
\end{tabular}

\subsection{Characterization of Renewable Polymer Graphite Composites}

The morphology of the random dispersed graphite in renewable polymer were observed using Optical Microscope. Meanwhile, the functional groups of the composites were identified by using PerkinElmer Fourier Transform Infrared Spectroscopy (FTIR) in the range of $400-4000 \mathrm{~cm}^{-1}$ of wavelength with $4 \mathrm{~cm}^{-1}$ of resolution. According to ISO 11358, thermal stability of the material were performed using Linseis Thermal Gravimetric Analysis (TGA) with $10 \mathrm{mg}$ of sample, setting temperature at $20{ }^{\circ} \mathrm{C}$ up to $1000{ }^{\circ} \mathrm{C}, 10^{\circ} \mathrm{C} / \mathrm{min}$ of heating rate and $0.3 \mu \mathrm{L}$ of flow rate using sample holder alumina crucible. The weight loss and derivative weight loss of the samples are measured. On the other hand, the tensile strength, elongation at break and modulus properties were determined by Universal Testing Machine (LLOYD Instruments) with load range $20 \mathrm{~N}$, cross head speed of $500 \mathrm{~mm} / \mathrm{min}$ and gauge length of $100 \mathrm{~mm}$ with $\pm 1 \%$ efficiency. This test was conducted as referring to ASTM D4329 [27] and ASTM D882 [28]. The electrical characterization is the conductivity of the renewable PG composites and their reliance. The volume resistivity of the prepared samples $\rho(\Omega)$ was determined by using a two point probe method with gold coating via a Keithley (USA) 6487 electrometer and then converted into electrical conductivity $\sigma(\mathrm{S} / \mathrm{m})$ using Equation (1):

$\rho=\sigma-1 R L l / g$

$l / g$ is the electrode geometrical factor ( $l$ is the total length of the electrode width and $g$ is the electrode distance), $L$ is the film thickness [29]. 


\section{Results and Discussion}

\subsection{Optical Morphology and Structural View}

In order to have a clear surface morphology of renewable PG composites, optical microscope (OM) images upon 100x magnification were taken as shown in Figure 3. The pure renewable polymer appears continuous morphology with clean and smooth yellowish surface. As the graphite filler increased from $5 \mathrm{wt} \%$ up to $30 \mathrm{wt} \%$, the flaky structure of graphite appears in the OM images tends to be connected and overlapped with each other at higher filler concentration. High concentration of graphite at $20 \mathrm{wt} \%$ observed the yellowish of renewable polymer turns to darker colour. At this point onwards, formation of graphite pathways in the polymer host are reveals. It is predicted that the graphite is not only a graphite but rather consists of several layers or aggregation of graphite sheets. They form amounts of hopping channels that were considered as alternative path to the electrical transportations [4], thus drives electron conductive properties of the graphite. This phenomenon will be discussed in the following section. Noted that the graphite contains functional groups such as hydroxyl and carboxylic groups which may have formed interconnected interface within the polymeric composites.

Analysis of the morphological structure of renewable PG composites remarks the good dispersion state of graphite within the renewable polymer matrix and a strong interaction between graphite filler with the polymer host. These would greatly enhance the physical and mechanical properties of the matrix.

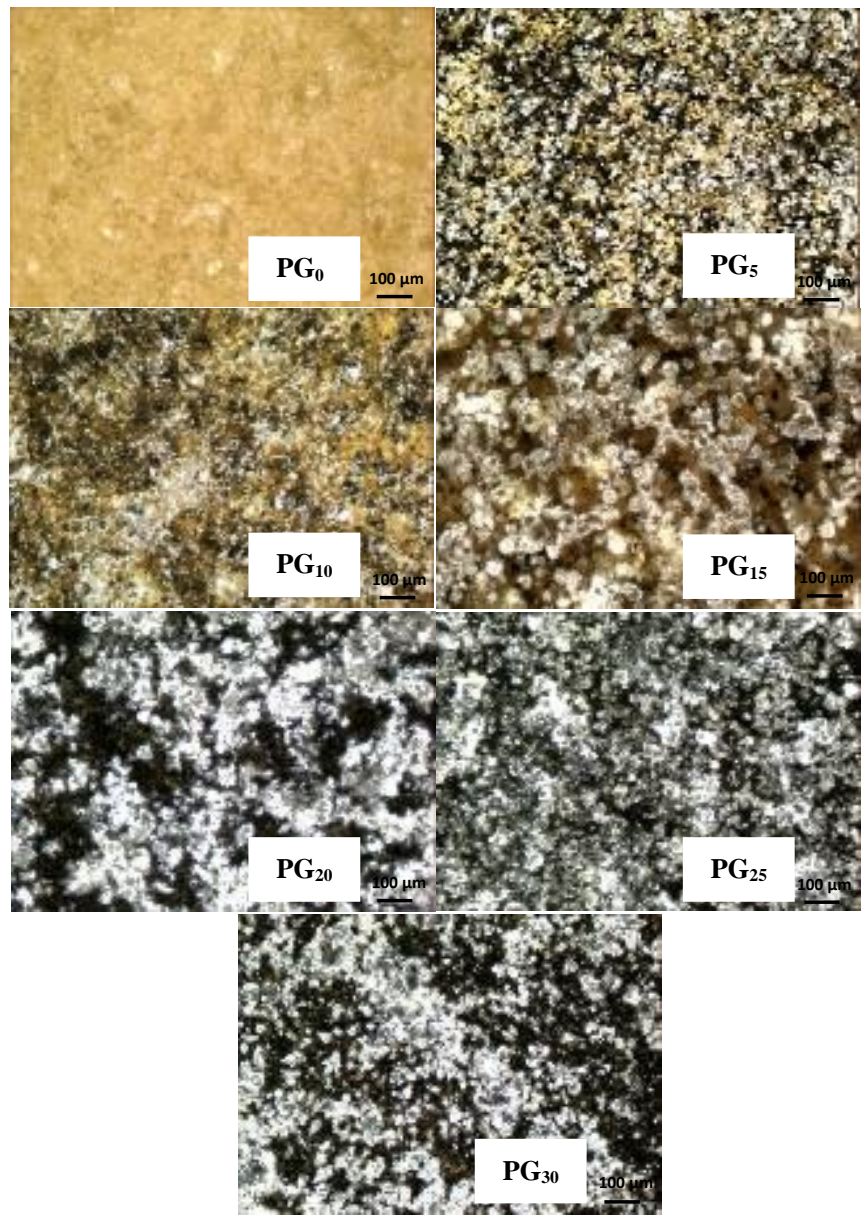

Fig. 3: Optical microscope images of renewable polymer graphite composites.

The functional and molecular composition of the resulting renewable PG composites was confirmed by FT-IR measurements. Figure 4 illustrates the FT-IR spectra of renewable PG composites with varying graphite weight loading $\left(\mathrm{PG}_{0}, \mathrm{PG}_{5}, \mathrm{PG}_{10}, \mathrm{PG}_{15}, \mathrm{PG}_{20}\right.$ $\mathrm{PG}_{25}$ and $\mathrm{PG}_{30}$ ) with pure renewable polymer as reference. There are no significant changes observed between those bands, exceptional for: higher shoulder at range $3200 \mathrm{~cm}^{-1}$ and at $2650.47 \mathrm{~cm}^{-1}$ , the decrease of polyether bands (C-O-C) at peak in a range 1300 $\mathrm{cm}^{-1}-1100 \mathrm{~cm}^{-1}$, and increasing aromatic bands $(\mathrm{C}=\mathrm{C})$ at peak range $1600 \mathrm{~cm}^{-1}-1400 \mathrm{~cm}^{-1}$. Two distinguished bands: a main peak centered at $1733.70 \mathrm{~cm}^{-1}$ and a relatively small shoulder at $1715 \mathrm{~cm}^{-1}$. The $1733.70 \mathrm{~cm}^{-1}$ peak is associated with the $-\mathrm{C}=\mathrm{O}$ groups and the shift to $1715 \mathrm{~cm}^{-1}$ results from hydrogen bonding hinting to the formation of urethane (NHCOO) bond. The disappearance of the peak at around $2260 \mathrm{~cm}^{-1}$ which is assigned to the free isocyanate group, confirming that all the diisocyanate are consumed in the reaction.

The peak at $3200 \mathrm{~cm}^{-1}$ is the stretching vibration absorption peak of the hydroxyl group in the structure of renewable PG composites, which is from the water molecule. This might be due to the hygroscopicity of the original graphite, graphite oxide (GO), and pretreated graphite [32]. FT-IR confirmed that renewable polymer grafting on functionalized graphite substantiated existence of the network-like structure even at 5 wt.\% of graphite content loading as shown in Figure 3.

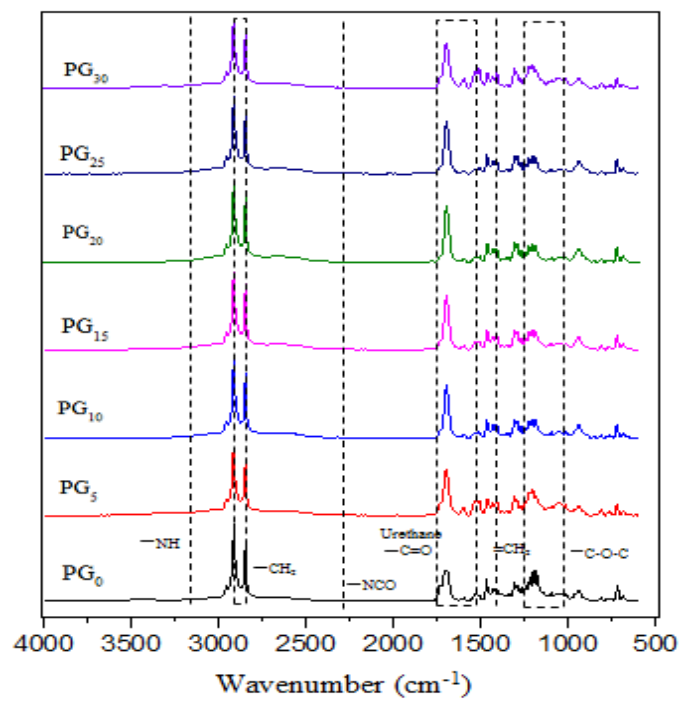

Fig. 4: FTIR spectrum of renewable PG composites.

\subsection{Thermo Gravimetric Analysis}

Thermo gravimetric analysis (TGA) profile was utilized to investigate the thermal stability of renewable PG composite materials. It is known that the disordered or amorphous carbons tended to be oxidized at around $500^{\circ} \mathrm{C}$. This is due to their lower activation energies for oxidation instead of the presence of a number of actives sites. Meanwhile, for the well graphitized structure, the carbonous material started to oxidize at a higher temperature up to range $800^{\circ} \mathrm{C}$ [33]. In addition, TGA is also useful method to characterize the quantity of organic materials grafted to carbonous materials. The organic material covalently attached with the surface of graphene-based materials was thermally stripped off in the temperature range 250 to $500^{\circ} \mathrm{C}$.

Theoretically, the initial weight loss below $100^{\circ} \mathrm{C}$ is attributed to the moisture retained in the sample. In this case, there is no significant mass loss detected in that region. As shown in Figure 5, the pure renewable monomer burn in a single step resulting in no residue in the sample holder at $650{ }^{\circ} \mathrm{C}$. On the other hand, the TGA curves of renewable polymer gives 3 distinct decomposition stages.

Accompanied with increasing temperature, the degradation started, weight loss of the composite is rapid. The 1 st and the 2 nd peak of renewable polymer degradation indicate the hard and soft segmented polyurethane respectively. In the first stage, the polyure- 
thane samples undergo spontaneous decomposition around $280^{\circ} \mathrm{C}$, regardless of the chain length of polyol used. This qualitative characterization of the renewable polymer degradation process was elaborated by the onset $T_{1 \text { on }}$ and maximum peak temperature $\mathrm{T}_{1 \max }$ of the first step and along with the second step $\mathrm{T}_{2 \mathrm{n}}$ and $\mathrm{T}_{2 \max }$.

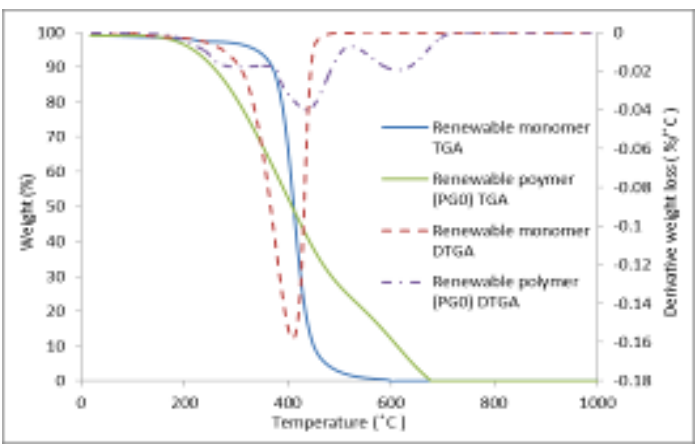

Fig. 5: Thermogravimetric profile and analysis data of renewable monomer and renewable polymer respectively.

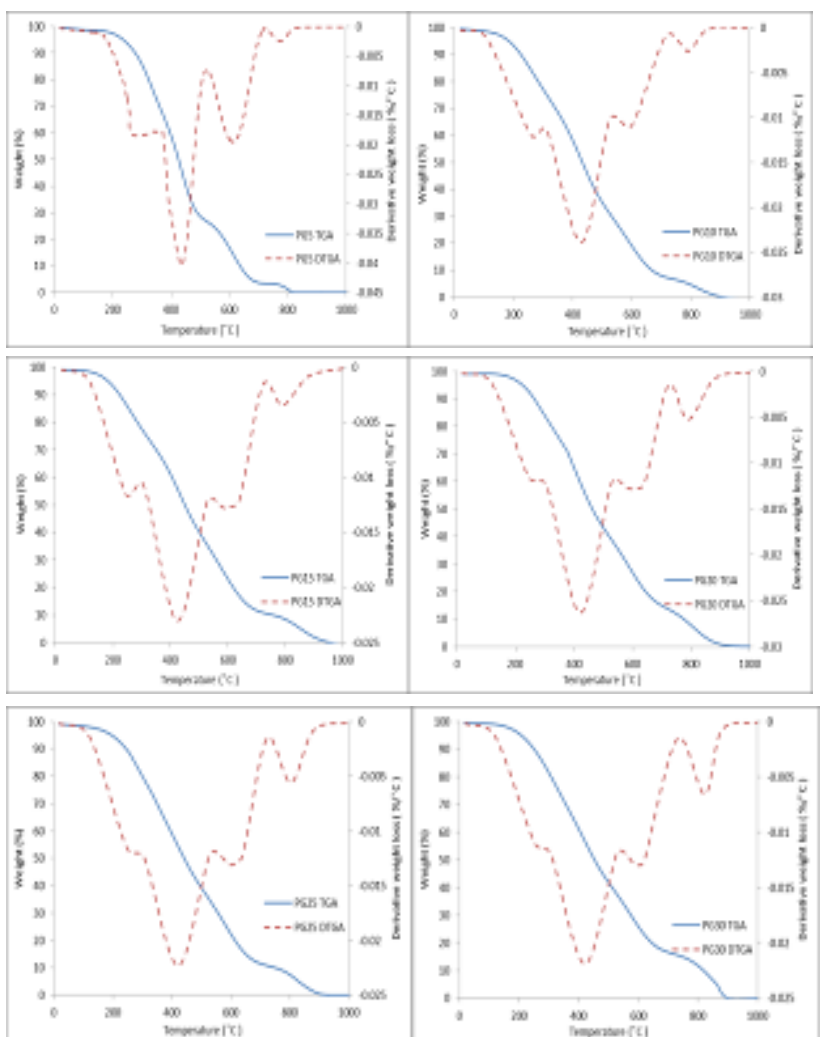

Fig. 6: Thermograms TGA and derivative weight loss of (a) $\mathrm{PG}_{5}$, (b) $\mathrm{PG}_{10}$ (c) $\mathrm{PG}_{15}$, (d) $\mathrm{PG}_{20}$, (e) $\mathrm{PG}_{25}$, and (f) $\mathrm{PG}_{30}$ of renewable PGcomposites

The weight loss and derivative weight loss curves of renewable $\mathrm{PG}$ with varying graphite loading $\left(\mathrm{PG}_{5}, \mathrm{PG}_{10}, \mathrm{PG}_{15}, \mathrm{PG}_{20}, \mathrm{PG}_{25}\right.$ and $\mathrm{PG}_{30}$ ) as shown in Figure 6 relatively indicate the pattern as mentioned. Clearly, the first break of the TG curves around $270{ }^{\circ} \mathrm{C}$ is due to the decrosslinking or post curing process. The second break around $400{ }^{\circ} \mathrm{C}-430{ }^{\circ} \mathrm{C}$ indicates the decomposition of polyurethane moiety into simpler molecules. The third break curves around $600{ }^{\circ} \mathrm{C}$ shows char residue. Previous researcher mentioned that superheated conditions inside the polymer matrix melt leading to extensive random scission of a polymer chain. Thus, the evolution of numerous chemical species which, trapped between graphite content layers, have more opportunity to undergo secondary reactions [34]. Therefore, some degradation pathways could be promoted leading to enhanced charring. This finding suggests that the effect of more effective char production during thermal decomposition of renewable PG composites derived from a chemical interaction between the polymer matrix and the graphite layer surface during thermal degradation. The increasing of weight loss of fourth break at $800{ }^{\circ} \mathrm{C}$ is assigned to oxidization of graphitized content with respect to increasing graphite loading in the renewable PG composites. The effect on flame retardancy is graphite content dependent as the more graphite filler in the renewable polymer, more char residue at the fourth break stage. Noticeable an increasing temperature in the first break at range $12{ }^{\circ} \mathrm{C}, 16{ }^{\circ} \mathrm{C}$ at second break, a slight fluctuate temperature at $9{ }^{\circ} \mathrm{C}$ and increasing up to $15{ }^{\circ} \mathrm{C}$ of decomposition temperature with increase of graphite content.

The TGA overall observed a good homogeneity of the composites was reached, under the preparation mode. A significant enhancement in thermal stability hints that the graphite contents in renewable polymer matrix resulting shifted temperature in all four stages to higher decomposition temperatures. Forming a slight higher value of char residue and expected oxidized graphite ratio were also observable in all samples prepared.

\subsection{Mechanical Behaviour}

The mechanical behavior of renewable PG composites are highly correlated with the intrinsic properties, amount, dispersion of the fillers, the properties of the polymer matrix, and the interaction between graphite content and polymer matrix $[35,36]$. Such properties as tensile strength, elastic modulus and elongation at break are expected to be improved with addition of graphite content in renewable polymer matrix. Figure 7-9 demonstrate the tensile strength, elastic modulus and elongation at break properties of renewable polymer graphite composites respectively.

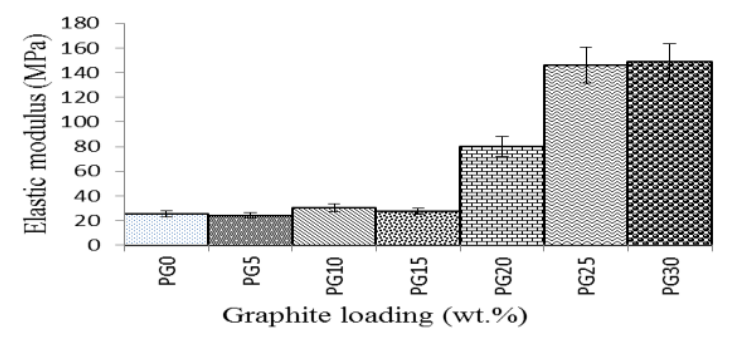

Fig. 7: Elastic modulus (MPa) of renewable $\mathrm{PG}_{0}, \mathrm{PG}_{5}, \mathrm{PG}_{10}, \mathrm{PG}_{15}, \mathrm{PG}_{20}$ $\mathrm{PG}_{25}$ and $\mathrm{PG}_{30}$ composites



Fig. 8: Tensile strength of renewable $\mathrm{PG}_{0}, \mathrm{PG}_{5}, \mathrm{PG}_{10}, \mathrm{PG}_{15}, \mathrm{PG}_{20}, \mathrm{PG}_{25}$ and $\mathrm{PG}_{30}$ composites



Fig. 9: Elongation at break $(\%)$ of renewable $\mathrm{PG}_{0}, \mathrm{PG}_{5}, \mathrm{PG}_{10}, \mathrm{PG}_{15}, \mathrm{PG}_{20}$ $\mathrm{PG}_{25}$ and $\mathrm{PG}_{30}$ composites 
The elastic modulus of the renewable PG composites in Figure 7 increased dramatically from $27 \mathrm{MPa}$ up to maximum $146 \mathrm{MPa}$; its about $440 \%$ increases than its former. This can be attributed to efficient load transfer between the graphite content and the polymer matrix resulting from the chemical bonding and physical bonding as aforementioned. Thus this renewable polymer graphite obeys the rule of mixtures in which any increment in filler loading will increase the modulus of the polymer composite [37]. The study also revealed that the tensile strength in Figure 8 shows an increased about $100 \%$, as increases from $3.5 \mathrm{MPa}$ up to maximum 6.5 MPa from the polymer host due to more graphite content in the renewable polymer matrix. Simillar behaviour has been observed for nanographite platelets (NGP) based polylactide (PLA) [13] and expanded graphite reinforced epoxy resin matrix [21]. It is expected that the strength of the composites would increase up to a maximum point where it achieved the strength of the filler itself. Knowing that as graphite content increased, renewable PG composites exhibit a classical brittle fracture, in which they do not exhibit a significant yield phenomenon before fracture.

The elongation at break or break displacement is decreased as indicated in Figure 9. The graphite content creates a discontinuity of renewable polymer in renewable PG composites, and at the same time creates a stress concentration phenomenon. Therefore when force is applied to the composites, the initial cracking occurs, and it becomes worse when the stress concentration occurs, and eventually causes structural failure. The increases of graphite content also contribute to the stiffening effect to the composites dramatically at $\mathrm{PG}_{20}, \mathrm{PG}_{25}$ and $\mathrm{PG}_{30}$. The modulus of the polymer composites can be improved by adding fillers that have a high modulus to the polymers that have a lower modulus, regardless of the interaction between them. Such a result would require a complex explanation, which is beyond any complex theories but it can be simplified by putting the extrinsic possess as a restrictive effect over the polymeric materials by restricting the motion and deformation of their molecular chains [38].

Hence, the compatibility and strong interaction between graphite content with/ within polymer matrix greatly enhances the dispersion as well as the interfacial adhesion, thus significantly improved the mechanical behavior of the renewable PG composites remarkably at the percolation threshold of the composites, $\mathrm{PG}_{20}$ $\mathrm{PG}_{25}$ and $\mathrm{PG}_{30}$.

\subsection{Electrical Measurement}

Electrical properties of renewable PG composites generally depend upon rate of dispersion and structure of conducting graphite content along with the properties of host polymers. Theoretically, addition of conductive graphite to a classical insulating renewable polymer can produce electrically conductive composite as the resistivity decreased [39], if the extrinsic concentration exceeds the percolation threshold. Figure 10 shows the variation of the electrical conductivity of renewable PG composites as a function of graphite content $\mathrm{PG}_{0}, \mathrm{PG}_{5}, \mathrm{PG}_{10}, \mathrm{PG}_{15}, \mathrm{PG}_{20}, \mathrm{PG}_{25}$ and $\mathrm{PG}_{30}$. The calculated electrical conductivities from the reciprocal of the resistivity increased by numerous orders of magnitude from $60-70 \mathrm{x}$ $10^{3} \mathrm{~S} / \mathrm{m}$ upon $\mathrm{PG}_{20}, \mathrm{PG}_{25}$ and $\mathrm{PG}_{30}$ composites. This can be explainable as PG composites with higher graphite concentration, a larger number of conductive pathways are available as aforementioned in Figure 3.

At zero and low graphite content $\left(\mathrm{PG}_{0}, \mathrm{PG}_{5}, \mathrm{PG}_{10}\right.$ and $\left.\mathrm{PG}_{15}\right)$, low electron mobility in the composites were observed due to low magnitude (lower than $10^{\circ} \mathrm{S} / \mathrm{m}$ ) of conductivity in which the electrical characteristic cannot be justified by the IV test. Contrary at higher graphite content, the internal insulating renewable polymer gaps tend to become smaller with increasing graphite filler assuming that the graphite are dispersed uniformly in the polymer matrix. This leads to smaller resistivity values with increasing filler content, favoring the occurrence of conductivity. A critical point where conduction path starts to trigger is called the percolation threshold. These percolation phenomena observable at $\mathrm{PG}_{20}$ as the conductivity of the system can be calculated. The increasing content of graphite results in a more complete conductive network and a greater conductivity. At certain point, the conductivity constantly retains the same regardless of the increasing content of graphite due to the initial properties of graphite. Since it is difficult to validate or invalidate the expected conduction mechanism by direct analytical measurements because of low currents implied. Hence suggesting different measurement techniques should be explore such as surface conductivity, DC conductivity, thermally stimulated DC current for better understanding the relationship between their electrical properties [39]. Based on the above observation, the improved mechanical interlocking between the well dispersed of graphite content and the renewable polymer matrix was partly responsible for the improved of its conductivity significantly.

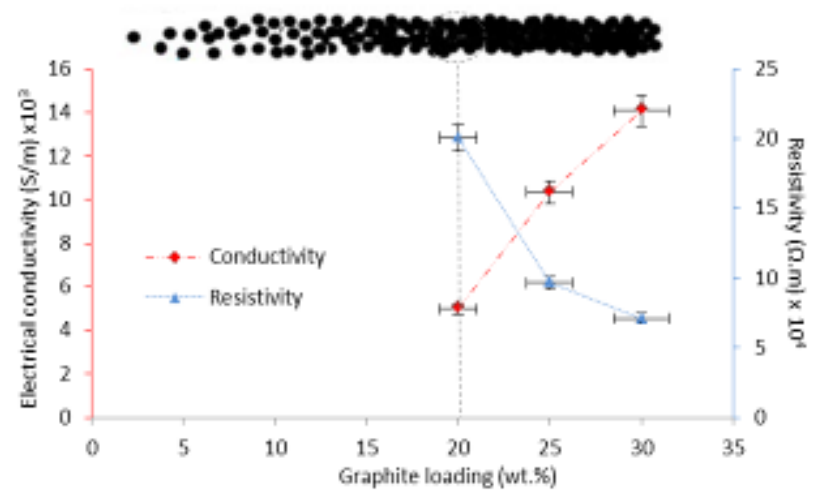

Fig. 10: The resistivity and electrical conductivity $(\sigma)$ of renewable PG composites as a function of graphite weight loading (wt.\%).

\section{Conclusion}

Renewable polymer reinforced with conducting graphite has shown a great interest due to unexpected enhancement in polymer matrix. Well dispersed between graphite in renewable polymer implies a strong interfacial bonding which showed correlations with good thermal properties, high strength, high modulus and improved electrical conductivity of the composites. The decomposition temperature, $\mathrm{T}_{\mathrm{g}}$ of all peaks are increases by at range $10^{\circ} \mathrm{C}$ higher than that of the neat renewable polymer for all samples prepared. The composites also exhibit $440 \%$ increases in elastic modulus and $100 \%$ improvement in tensile strength than its former. Meanwhile, the percolation threshold at $\mathrm{PG}_{20}, \mathrm{PG}_{25}$ and $\mathrm{PG}_{30}$ give values of the conductivity at range $60-70 \times 10^{3} \mathrm{~S} / \mathrm{m}$. In short, the graphite conducting continuity in non-conducting material provided a motivated considerable interest in the studies of renewable polymer graphite composite materials with enhanced performances.

\section{Acknowledgement}

The authors would like to thank Universiti Tun Hussein Onn Malaysia (UTHM), Johor, under Fundamental Research Grant Scheme (Phase 1/2015), vot 1534 and Ministry of Education Malaysia through MyBrain15 (MyPhD) for supporting this research.

\section{References}

[1] S.M. Zhang, L. Lin, H. Deng, X. Gao, E. Bilotti, T. Peijs, Q. Zhang and Q. Fu, Synergistic effect in conductive networks constructed with carbon nanofillers in different dimensions, Express Polym. Lett., vol. 6, no. 2, pp. 159-168, 2012.

[2] N. Yamamoto, R. G. DeVilloria, H. G. Cebeci, and B. L. Wardle, Thermal and electrical transport in hybrid woven composites reinforced with aligned carbon nanotubes, Collect. Tech. Pap. AIAA/ASME/ASCE/AHS/ASC Struct. Struct. Dyn. Mater. Conf., pp. 0-10, 2010. 
[3] M. C. Alessandro Chiolerio Parvin Jagdale, Mauro Giorcelli, Stefano Bianco, Alberto Tagliaferro, Electrical properties of CNT Based polymeric matrix nanocomposites, Carbon Nanotub. Polym. Nanocomposites, no. 11, pp. 215-230, 2011.

[4] L. W. Yang, X. S. Zhang, H. T. Liu, and M. Zu, Thermal resistant, mechanical and electrical properties of a novel ultrahigh-content randomly-oriented CNTs reinforced $\mathrm{SiC}$ matrix composite-sheet, Compos. Part B Eng., vol. 119, pp. 10-17, 2017.

[5] Changlei Xia, Shifeng Zhang, Han Ren, Sheldon Q. Shi, Hualiang Zhang, Liping Cai and Jianzhang Li., Scalable fabrication of natural-fiber reinforced composites with electromagnetic interference shielding properties by incorporating powdered activated carbon, Materials (Basel)., vol. 9, no. 1, pp. 1-9, 2016.

[6] V. Sridhar, I. Lee, H. H. Chun, and H. Park, Graphene reinforced biodegradable poly(3-hydroxybutyrate-co-4-hydroxybutyrate) nano-composites, Express Polym. Lett., vol. 7, no. 4, pp. 320-328, 2013.

[7] V. Sridhar, I. Lee, H.H. Chun and H. Park., Graphene-based composite materials, vol. 442, no. July, 2006.

[8] T. Kuila, S. Bose, A. K. Mishra, P. Khanra, N. H. Kim, and J. H. Lee, Effect of functionalized graphene on the physical properties of linear low density polyethylene nanocomposites, Polym. Test., vol 31 , no. 1, pp. 31-38, 2012

[9] K. M. F. Shahil and A. A. Balandin, Thermal properties of graphene and multilayer graphene: Applications in therma interface materials, Solid State Commun., vol. 152, no. 15, pp. 1331-1340, 2012.

[10] X. Tian, M. E. Itkis, E. B. Bekyarova, and R. C. Haddon, Anisotropic Thermal and Electrical Properties of Thin Thermal Interface Layers of Graphite Nanoplatelet-Based Composites, Sci. Rep., vol. 3, pp. 1-6, 2013.

[11] H. Wang, Synthesis Of Graphene And Its Applications For DyeSensitized Solar Cells By, 2013.

[12] Ling Du, "High conductive epoxy/graphite polymer composite bipolar plates in proton exchange membrane (PEM) full cell," $p$ 277, 2008.

[13] V. Singh, D. Joung, L. Zhai, and S. Das, Progress in Materials Science Graphene based materials: Past, present and future, vol. 56, pp. 1178-1271, 2011.

[14] N. K. Sidhu and A. C. Rastogi, Vertically aligned ZnO nanorod core-polypyrrole conducting polymer sheath and nanotube arrays for electrochemical supercapacitor energy storage., Nanoscale Res. Lett., vol. 9, no. 1, p. 453, 2014.

[15] W. P. Shih et al., Flexible temperature sensor array based on a Graphite-Polydimethylsiloxane composite, Sensors, vol. 10, no. 4 pp. 3597-3610, 2010.

[16] L. M. Zhao, X. Feng, X. J. Mi, Y. F. Li, H. F. Xie, and X. Q. Yin, Mechanical reinforcement and shape memory effect of graphite nanoplatelet-reinforced epoxy composites, J. Intell. Mater. Syst. Struct., vol. 26, no. 12, pp. 1491-1497, 2015.

[17] E. Narimissa, Uniaxial extensional rheological analysis of biodegradable polylactide-nanographite platelet nanocomposites through constitutive equations, no. August, 2013.

[18] W. H. Awad and C. A. Wilkie, Investigation of the thermal degradation of polyurea: The effect of ammonium polyphosphate and expandable graphite, Polymer (Guildf)., vol. 51, no. 11, pp. 2277-2285, 2010.

[19] D. Cai, K. Yusoh, and M. Song, The mechanical properties and morphology of a graphite oxide nanoplatelet/polyurethane composite., Nanotechnology, vol. 20, no. 8, p. 85712, 2009

[20] A. Yasmin, J. J. Luo, and I. M. Daniel, Processing of expanded graphite reinforced polymer nanocomposites, Compos. Sci. Technol., vol. 66, no. 9, pp. 1179-1186, 2006.

[21] A. Z. M. Rus, N. M. Abdullah, and M. F. L. Abdullah, Interconnected interface enhanced electrical properties of graphite in bio-based epoxy from insulating to conductor composites, Indian J. Sci. Technol., vol. 8, no. 17, pp. 8-12, 2015.

[22] M. M. Gudarzi and F. Sharif, Enhancement of dispersion and bonding of graphene-polymer through wet transfer of functionalized graphene oxide, Express Polym. Lett., vol. 6, no. 12, pp. 1017-1031, 2012.

[23] S. C. \& J. H. Xiao Yang, Jun Hu, Understanding the Percolation Characteristics of Nonlinear Composite Dielectrics, Sci. Reports, Publ. online 1 August 2016; | doi10.1038/srep30597, vol. 6, no. 2, pp. 366-377, 2016.

[24] J. Li, J. Li, and M. Li, Preparation of expandable graphite with ultrasound irradiation, Mater. Lett., vol. 61, no. 28, pp. 5070-5073, 2007.
[25] N. M. Abdullah and M. F. L. Abdullah, Mechanical Reinforcement of Conductive Graphite / Biopolymer Thin Film Composite, ARPN J. Eng. Appl. Sci., vol. 10, no. X, pp. 1-4, 2015.

[26] N. Munirah, A. Zafiah, M. Rus, and M. F. L. Abdullah, Jurnal Teknologi Synergistic Influence Of Graphite On Biopolymer Composites Properties, vol. 32, pp. 11-19, 2015.

[27] I. By and S. A. Cleveland, "Standard Test Methods," pp. 216-241, 2011.

[28] ASTM, D 882: Standard Test Method for Tensile Properties of Thin Plastic Sheeting, Astm, vol. 14, pp. 1-10, 2002.

[29] S. Kim, J. Xu, and S. Liu, Production of biopolymer composites by particle bonding, Compos. Part A Appl. Sci. Manuf., vol. 41, no. 1, pp. 146-153, 2010.

[30] S. Zhou, Y. Chen, H. Zou, and M. Liang, Thermally conductive composites obtained by flake graphite filling immiscible Polyamide 6/Polycarbonate blends, Thermochimica Acta 566, (2013) pp. 84 91

[31] Anika Zafiah M. Rus, Nur Munirah Abdullah and M.F.L. Abdullah Interconnected Interface Enhanced Electrical Properties of Graphite in Bio-based Epoxy from Insulating to Conductor Composites, Indian Journal of Science and Technology, Vol 8(17) (2015) IPL0159

[32] K. Liu, B. He, and J. Li, Conducting graphite/ cellulose composite film as a candidate for chemical vapor-sensing material, Peerreviewed article in BioResources 9 (3) (2014) pp. 5279- 5289.

[33] S. Stankovich, D.A. Dikin, R.D. Piner, K.A. Kohlhaas, A. Kleinhammes, Y. Jia, Y. Wu, S.B.T. Nguyen, R.S. Ruoff, Synthesis of graphene-based nanosheets via chemical reduction of exfoliated graphite oxide, Carbon 45 (2007), 1558-1565.

[34] Carola Esposito Corcione and Mariaenrica Frigione, Characterization of Nanocomposites by Thermal Analysis, Materials, 5 (2012).

[35] A.Z.M Rus, N.M Abdullah, M.F.L. Abdullah and M.I.F. Idris, Graphite/Bio-Based Epoxy Composites: The Mechanical Properties Interface Applied Mechanics and Materials Vols. 799-800 (2015) pp. 115-119

[36] Anika Zafiah M. Rus, Nur Munirah Abdullah and M.F.L. Abdullah, Mechanical Behavior of Ultra Violet (UV) Curable Renewable Polymer/Graphite (PG) Indian Journal of Science and Technology, Vo 9(48) (2016)

[37] J. Ervina, M. Mariatti and S. Hamdan, Effect of Filler Loading on the Tensile Properties of Multi-walled Carbon Nanotube and Graphene Nanopowder filled Epoxy Composites, Procedia Chemistry 19 (2016) pg. $897-905$

[38] Chien-Lin Huang, Ching-Wen Lou, Chi-Fan Liu, Chen-Hung Huang, Xiao-Min Song and Jia-Horng Lin, Polypropylene/Graphene and Polypropylene/Carbon Fiber Conductive Composites: Mechanical, Crystallization and Electromagnetic Properties, Appl. Sci., 5, (2015) 1196-1210

[39] T.S. Bachari, Electric Properties Of Polyvinyl Acetate (PVA)- Polyol And Prepared Sulfonated Phenol Formaldehyde Resin (SPF) Bulk Samples Composite, Asian Journal of Applied Science and Engineering, Volume 3, No 2 (2014). 